\title{
Influence of Insulation Thermal Aging on the Temperature Assessment in Electrical Machines
}

\author{
Vincenzo Madonna, Member, IEEE, Paolo Giangrande, Senior Member, IEEE, and \\ Michael Galea, Senior Member, IEEE
}

\begin{abstract}
Thermal modeling and temperature assessment of electrical machines often rely on the use of lumped-parameter thermal networks. A historic limitation of analytical thermal models is their need for an experimental fine-tuning, necessary for selecting the appropriate values of thermal conductivity and convection heat transfer coefficients. This evaluation procedure is commonly carried out at the design stage of a new machine, by assuming that its thermal behavior will remain unchanged throughout its whole lifetime. This paper demonstrates, through an in-depth experimental investigation, how the capability of heat extraction from a machine's hot spot towards the coolant can be strongly affected by the level of thermal aging of its insulation system. Based on the experimental findings, a decrement of the winding equivalent thermal conductivity is noted as the thermal aging accumulates, with a corresponding progressive increment in hot-spot temperature.
\end{abstract}

Index Terms-Thermal Analysis, LPTN, Aging, Physics of Failure, Design of Experiments, Electrical Machines

\section{NOMENCLATURE}

CFD Computational fluid dynamics.

EM Electrical machine.

FE Finite element

LPTN Lumped-parameter thermal network.

$B x \quad \mathrm{x}^{\text {th }}$ percentile of failure time.

d Mass density.

c Specific heat capacity.

C Thermal capacity.

ff Slot copper fill factor.

$i_{g} \quad$ Impregnation goodness.

$I_{D C} \quad$ DC current.

$h \quad$ Convection heat transfer coefficient.

$k \quad$ Thermal conductivity.

$L \quad$ Axial (active) length.

$L^{*} \quad$ Characteristic length.

$n \quad$ Number of turns.

$\mathrm{Nu} \quad$ Nusselt number.

$P_{J} \quad$ Joule losses.

$R a \quad$ Rayleigh number.

$S_{\text {cond }} \quad$ Conductor cross sectional area.

$t$ Time.

$v \quad$ Generic volume.

$\alpha \quad$ Copper electrical resistivity variation coefficient.

Manuscript received February 17, 2020; revised April 27, 2020; accepted June 06, 2020.

This work was partially funded from the Clean Sky 2 Joint Undertaking under the European Union's Horizon 2020 research and innovation programme under grant agreement no. 807081.

This work was also partially funded by the University of Nottingham Propulsion Futures Beacon. (Corresponding Author: Vincenzo Madonna)

V. Madonna, P. Giangrande and M. Galea are with the Power Electronics, Machines and Control Research Group (PEMC), University of Nottingham, UK. (email: Vincenzo.madonna1@nottingham.ac.uk)

M. Galea is also with the Key Laboratory of More Electric Aircraft Technology of Zhejiang Province, Ningbo 315100, China.
Slot thermal capacity correction factor. Electrical conductivity.

Temperature.

Natural convection corrective factor.

\section{INTRODUCTION}

Lumped-parameter thermal networks (LPTNs) are a convenient and largely employed tool for evaluating the temperature distribution in electrical machines (EMs). They are able to precisely model the thermal behavior of both naturally- and forced- cooled EMs, adopting either air [1] or liquid $[2,3]$ as the main coolant. As opposed to other thermal modeling techniques e.g., computational fluid dynamics (CFD) and finite element (FE), an LPTN comprises a muchreduced computational cost. In fact, the transient temperature distribution within an EM via an LPTN is essentially obtained by solving a set of differential equations [4]. Clearly, the higher the discretization - i.e., the number of nodes to be considered - the larger the number of equations to be solved, and thus the computational burden. Usually, a machine designer is only interested in obtaining the temperature for a particular sub-assembly or sub-section of the EM, e.g., the winding [5-7], and/or the permanent magnets (PMs), and thus reduced complexity LPTNs can be built [6]. In addition, models for very short duty EMs, whose order is as low as one (i.e., comprising a single thermal mass), can provide a fairly accurate indication of the winding temperature profile [8].

Irrespective of the LPTN's order, a main drawback / limitation of this thermal modeling technique is the need of determining a number of so-called critical parameters $[6,9$, 10]. The temperature assessment accuracy is strongly influenced by the chosen value of a) the thermal conductivity within multi-material volumes (i.e., winding), b) the convection heat transfer coefficients c) the thermal capacities and d) the interference gaps (e.g., the non-ideal fitting between housing and stator core surfaces) [4]. The fine-tuning of these critical parameters is conventionally accomplished through experimental measurements, performed either on the EM (when already available) or on a thermally-equivalent prototype (e.g., a motorette that physically emulates the EM in terms of geometry and materials) [4, 11]. Essentially, conductivities, convection coefficients and interference gaps values are varied within a physically-admissible range, in order to match as precisely as possible the measured temperatures $[12,13]$.

The experimental tests, necessary for the LPTN fine-tuning, are usually executed without having any information on the "aging state" of the modeled EM. If they are carried out on a full machine, it is likely that the latter has already been in service for a certain time, whilst a motorette is conceivably newly manufactured. In either case, the assumption is that the thermal behavior of a given EM will 
not change throughout its whole lifetime. In other words, the numerical values of the critical parameters are presumed to not be influenced by the EM aging level. However, recent studies have proved that the thermal aging can considerably affect the physical and dielectric properties of the electrical insulating materials employed in EMs [14-17]. As a direct consequence of the thermal aging, on one hand, the capability to withstand a voltage applied across the insulation system is severely compromised (as discussed in Section V), while on the other hand, the insulation degradation results in an alteration of the EM thermal performance. Focusing on the second effect, any developed LPTN should be properly updated in order to take into account the effects of this thermal aging, otherwise misleading temperatures can be obtained.

Existing methodologies [18, 19], mainly based on Kalman filters, can be adopted for dynamically correcting LPTNs' parameters and enhancing the temperature calculation accuracy. However, these strategies are primarily aimed at online temperature assessment, and do not provide a direct relationship between LPTNs' parameters variation and insulation thermal aging. In fact, although the thermal degradation of the EM insulation is widely addressed in literature [20], its link to the EM thermal modelling is usually omitted, particularly for impregnated, random wound EMs (which represent the most common winding arrangement in low voltage EMs). An exception is represented by [21], where an investigation on Litz-type winding is carried out. The main outcome of [21] indicates a strong correlation between insulation thermal aging and equivalent thermal resistance for the particular case of Litz-wire winding topology.

This paper is therefore focused on investigating the influence and effects that insulation thermal aging can have on the accuracy of the temperature prediction in EMs. In this work, the EM considered comprises impregnated random windings. The selected EM is initially modelled through an LPTN as presented in Section III, which is experimentally fine-tuned according to the procedure discussed in Section IV. The tests for this fine-tuning are performed on unaged motorettes. Then, the motorettes are thermally aged at a temperature above the insulation system thermal class, as detailed in Section V. After each thermal exposure, the LPTN's fine-tuning is repeated to verify how its parameters vary as the thermal aging accumulates. In Section VI, the variation of thermal behavior is correlated with the insulation cumulative damage, and the applicability and benefits deriving from the implementation of the proposed methodologies are discussed. Section VII concludes the paper by summarizing the main results of the presented study.

\section{INITIAL THERMAL MODEL}

Considerations on the building procedure adopted for developing the LPTN are given in this Section. Hence, its content is essential for supporting the discussion addressed in Sections V and VI, where the LPTN is employed for investigating the impact of the insulation thermal aging on the heat transfer within an EM.

\section{A. Motorette description}

The motorette illustrated in Fig. 1 is used as test sample for the presented investigation. It comprises a total of 6 slots with an impregnated single layer concentrated winding (i.e., three coils in total) and is cooled by natural air convection. The motorette mirrors a stator's section of a 12 slot / 10 pole PM synchronous machine (PMSM) whose main design parameters are listed in Table I. The main focus of this work is to understand how insulation aging affects the prediction accuracy of LPTNs used to assess an EM's thermal behavior. Thus, the rotor has not been modeled in the LPTN.

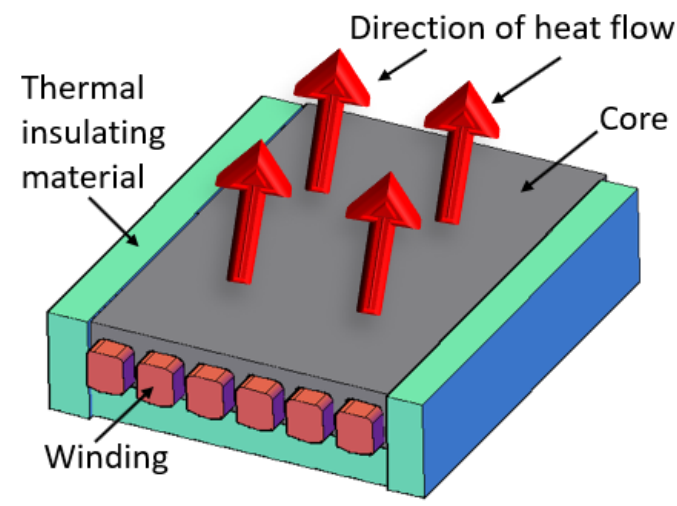

Fig. 1. Motorette installed on a thermal insulating material.

TABLE I

Main Design Parameters of THE CASE-STUdy PMSM

\begin{tabular}{cc}
\hline \hline Parameter & Data \\
\hline Slot number & 12 \\
Pole number & 10 \\
Axial length & $84 \mathrm{~mm}$ \\
Stator outer diameter & $60 \mathrm{~mm}$ \\
Winding configuration & Concentrated \\
Turns per coil & 80 \\
Winding wire bare diameter & $0.400 \mathrm{~mm}$ \\
Winding wire grade & Grade 2 \\
Insulation thermal class & $200{ }^{\circ} \mathrm{C}$ \\
Impregnation & VPI epoxy resin \\
\hline \hline
\end{tabular}

The motorette is horizontally placed on a thermal insulating material, which prevents any heat flow from the stator bore. Similar thermal separators are also employed for insulating the two lateral ends of the lamination stack. Additionally, it has been decided to not include any housing, as the latter would only increase the LPTN complexity, without providing any practical benefits to the main purpose of this work. Therefore, it can be easily observed that at steady-state, any heat generated within the winding volume can only flow towards the stator outer surface, where it is dissipated through natural convection, as indicated by the red arrows in Fig. 1.

\section{B. LPTN building procedure}

The LPTN of the previously described motorette has been built and its layout is shown in Fig. 2. By exploiting the geometrical symmetries, a single slot has been modelled. The temperature of interest is the one identified as $\theta_{h s}$, which represents the winding hot-spot. The parameter $\theta_{\text {ext }}$ indicates the stator external temperature, which is considered to be uniform over the whole outer surface. The tangential resistances of the stator teeth have purposely been omitted, as they provide a negligible contribution, due to their being in series with the slot tangential resistances as well as with the slot liner ones. The LPTN is thermally-symmetrical along the vertical centerline, and thus the nodes identified with the same number in Fig. 2 are isothermal. These can be merged into single nodes, further reducing the LPTN's order down to the sixth (i.e., a total of 6 thermal capacities). Such a merging operation is automatically executed when the LPTN is 
implemented in Matlab Simulink ${ }^{\circledR}$, using the thermal library of the Simscape ${ }^{\mathrm{TM}}$ toolbox.

The only heat source is represented by the Joule losses originated within the winding, thus iron losses are not included. This allows for a single, well defined source of loss $[4,6]$, which is particularly handy when performing the experimental tuning through a DC excitation, as in the case of this work. This assumption is valid for this study, as the presence of additional losses, other than Joule's ones, would only provide an offset for the winding's hot-spot temperature. Accordingly, the Joule losses along the active length of a coil (i.e., within a single slot) can be calculated as in (1), where $I_{D C}$ is the winding DC current, $n$ is the number of turns per coil, $L$ is the active length of the lamination stack, $\rho(\theta)$ is the copper resistivity at temperature $\theta$ and $S_{\text {cond }}$ is the equivalent conductor cross-sectional area.

$$
P_{J}=I_{D C}^{2} \cdot n \cdot L \cdot \rho(\theta) / S_{\text {cond }}
$$

In the presented model it is assumed that all the heat generated within the end winding volume is directly dissipated to the ambient air via natural convection through their external surface. That is, no heat is axially transferred from the end winding to the active coil volume (and vice-versa).

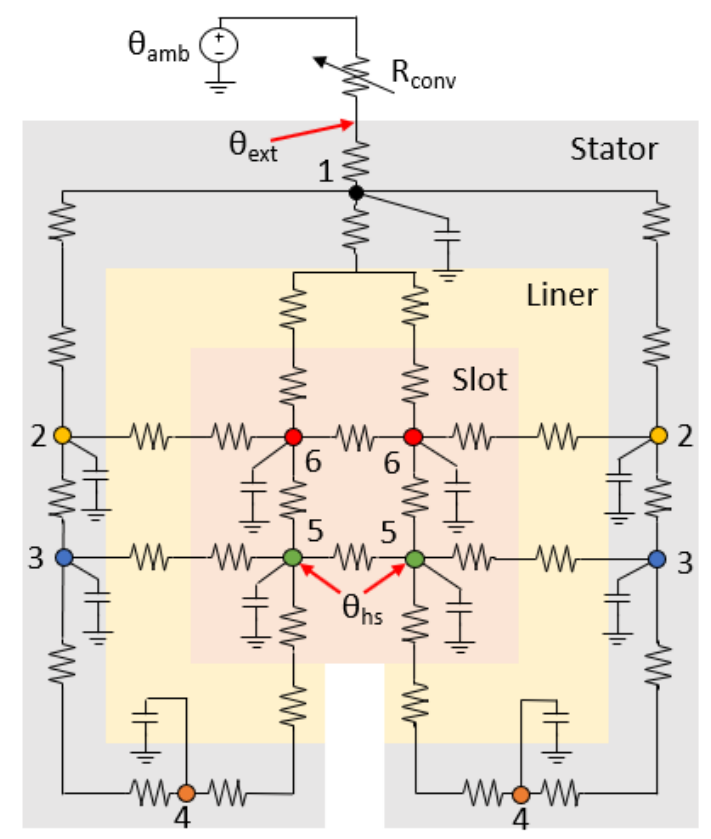

Fig. 2. Motorette's LPTN.

During a transient thermal simulation, the copper resistivity might considerably vary as a function of the EM operating temperature. Therefore, $\rho(\theta)$ used in the LPTN simulation is generally calculated relying on the "expected" steady-state temperature [22, 23]. Since this methodology might introduce inaccuracies in the Joule losses computation, a different approach is used here, where the actual copper resistivity at any generic time $(t+1)$ is determined according to the winding temperature at time $t$. The copper resistivity is related to the temperature through (2), where $\alpha$ is a constant equal to $3.93 \cdot 10^{-3}{ }^{\circ} \mathrm{C}^{-1}[4]$ and $\rho\left(0^{\circ} \mathrm{C}\right)$ is the copper electrical resistivity at $0{ }^{\circ} \mathrm{C}$ (i.e., $1.549 \cdot 10^{-8} \Omega \cdot \mathrm{m}$ ).

$$
\rho(\theta)=\rho\left(0{ }^{\circ} \mathrm{C}\right) \cdot[1+\alpha \cdot \theta]
$$

The Joule losses at time instant $t$ can be then obtained as indicated in the block diagram reported in Fig. 3, which can be easily implemented in a Simscape ${ }^{\mathrm{TM}}$ model. It is worth noting that in Fig. 3 it has been modelled a single slot node for the sake of representation clarity. The same procedure needs thus to be repeated for each of the slot nodes (according to the chosen discretization level).

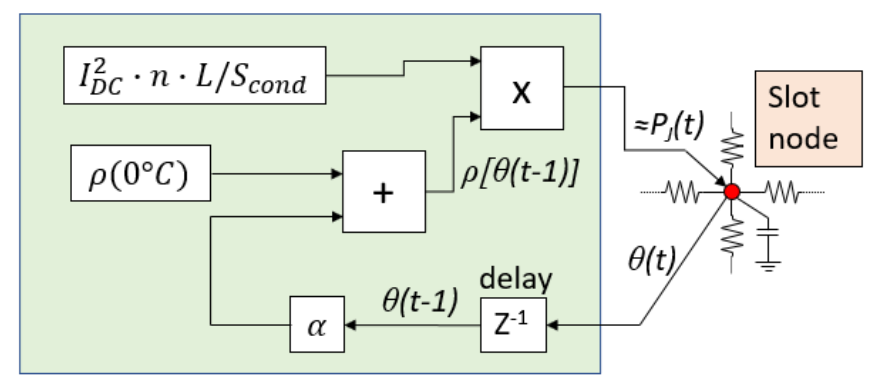

Fig. 3. Block diagram for dynamic resistivity computation.

In the proposed LPTN, the slot has been thermally homogenized and modelled as a compound of two materials [24-26], namely copper and impregnating resin. Thus, its equivalent thermal conductivity, in both radial and tangential directions, is calculated according to (3) [24], where ff is the copper fill factor, while $k_{c u}$ and $k_{\text {res }}$ are the copper and impregnation resin thermal conductivities respectively.

$$
k_{\text {slot }}=k_{\text {res }} \cdot \frac{(1+f f) k_{c u}+(1-f f) k_{r e s}}{(1-f f) k_{c u}+(1+f f) \cdot k_{r e s}}
$$

Equation (3) tends to over-estimate the equivalent conductivity value, because it implies an impregnation goodness $i_{g}$ equal to $100 \%$, i.e., no air voids are present among wires. This condition is very challenging to be achieved in actual impregnated windings and the presence of air in the slot significantly deteriorates the slot equivalent thermal conductivity. Since the impregnation goodness is a parameter difficult to know a-priori, the precise numerical value of $k_{s l o t}$, which accounts for the impregnation quality, is then experimentally identified $[2,11]$. Additionally, it is expected that its value does not remain constant throughout the EM lifetime owing to the insulation thermal aging, as it will be demonstrated in Sections V and VI. Therefore, in this work, the main purpose of (3) is to actually provide an upper boundary to the numerical value of $k_{\text {slot }}$, and thus limit the search space during the LPTN's calibration procedure.

Similarly, the slot thermal capacities are calculated assuming a compound of two materials, whose equivalent mass density is calculated as reported in (4) and the equivalent specific heat capacity is calculated as in (5), where $d_{c u}$ and $d_{r e s}$ are the copper and resin mass densities respectively, while $c_{c u}$ and $c_{r e s}$ are the copper and resin specific heat capacities respectively.

$$
\begin{aligned}
& d_{\text {slot }}=d_{c u} \cdot f f+d_{\text {res }}(1-f f) \\
& c_{\text {slot }}=c_{c u} \cdot f f+c_{\text {res }}(1-f f)
\end{aligned}
$$

Again, because (4) and (5) do not account for the impregnation goodness, their correct values need to be experimentally defined. In general, the thermal capacity of a generic EM portion, whose volume is $v$, is provided by (6).

$$
C=c \cdot d \cdot v
$$

Therefore, in order to account for the non-perfect impregnation, the slot thermal capacity is determined as in (7), where $S_{\text {slot }}$ is the slot cross sectional area and $\gamma\left(i_{g}\right)<1$ is a corrective factor, which depends on the impregnation goodness and it is experimentally determined. 


$$
C_{\text {slot }}=c_{\text {slot }} \cdot d_{\text {slot }} \cdot S_{\text {slot }} \cdot L \cdot \gamma\left(i_{g}\right)
$$

In LPTNs, the natural air convection is usually modelled through a fixed value resistance $[5,6,27]$, that is a function of the natural convection heat transfer coefficient $h_{0}$ between the considered surface (generally the external housing) and the ambient air. An average frame surface is assumed for computing $h_{0}$ [6]. Such an approach, which is valid when modelling steady-state thermal conditions, can deliver inaccurate results during transient analyses. In fact, $h_{0}$ is strongly influenced by the actual external surface temperature. Therefore, in this work the standard, fixed-value convection heat transfer resistance is replaced by a variable resistance, which dynamically adjusts its value according to the instantaneous temperature of the heat transfer surface $\theta_{\text {ext }}$. As the motorette does not comprise a housing, the heat transfer surface coincides with the lamination core outer surface, in the study at hand. The latter can be modelled as the upper surface of a hot plate [28]. Assuming a fixed ambient temperature $\theta_{a m b}$, the convection heat transfer coefficient, as a function of the surface temperature, can be calculated as in (8) [28], where $k_{\text {air }}$ is the thermal conductivity of air, $N u$ is the Nusselt number and $L^{*}$ is the characteristic length, defined as the ratio between the flat plate surface area $A_{\text {ext }}$ and its perimeter $P_{\text {ext }}$.

$$
h_{0}\left(\theta_{\text {ext }}\right)=k_{\text {air }} \cdot N u\left(\theta_{\text {ext }}\right) / L^{*}
$$

For the operating temperature range of conventional EMs, the Nusselt number can be approximated by the empirical relationship expressed in (9) [29], where $R a$ is the Rayleigh number.

$$
N u\left(\theta_{\text {ext }}\right) \approx 0.54 \cdot R a\left(\theta_{\text {ext }}\right)^{\frac{1}{4}}
$$

The Rayleigh number is a function of the temperature difference between the external surface and ambient air and it is calculated as in (10) [28], where $g$ is the gravitational acceleration, $\beta$ is the volumetric thermal expansion coefficient, $v$ is the kinematic viscosity and $\alpha_{d}$ is the thermal diffusivity.

$$
R a\left(\theta_{\text {ext }}\right)=\frac{g \cdot \beta \cdot\left(\theta_{\text {ext }}-\theta_{a m b}\right) \cdot\left(L^{*}\right)^{2}}{v \cdot \alpha_{d}}
$$

By replacing (10) in (9) and (9) in (8), the natural air convection resistance $R_{\text {conv }}$ can be obtained as detailed in the block diagram reported in Fig. 4. In Fig. 4, the parameter $\psi$ is a non-dimensional correction factor, whose value will be experimentally identified as detailed in Section IV. At the beginning of the thermal simulation, its preliminary value is set equal to one. Since the Nusselt number calculated by (9) is an empirical approximation [29], the introduction of the parameter $\psi$ is necessary for compensating any discrepancy between predicted and measured core's outer surface temperature.

The considerations on the modelling methodologies for 1) slot equivalent thermal conductivity, 2) slot thermal capacitance and 3) natural convection heat transfer coefficient here argued, aim to enhance the LPTN accuracy, particularly during transient operations. This is a prerequisite for better evaluating the impact of the insulation thermal aging on the EM thermal performance. The methodologies presented in this Section (particularly the block diagram in Fig. 4) represent an advancement with respect to standard analytical thermal modelling techniques, which usually consider a constant convection heat transfer coefficient $[6,9]$.

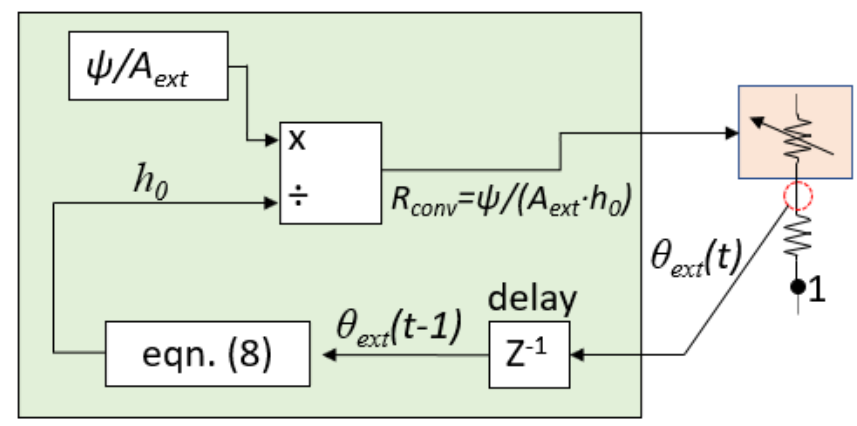

Fig. 4. Block diagram for the dynamic computation of the natural convection resistance.

\section{EXPERIMENTAL FINE-TUNING OF CRITICAL THERMAL PARAMETERS}

A preliminary thermography analysis has been carried out before impregnating the motorettes for identifying the winding's hot-spot location(s), and distributing the thermal sensors accordingly. DC current is circulated through the winding, until the thermal steady-state condition is reached. The result of the infrared signature analysis is shown in Fig. 5 , where the hot-spot location is clearly identifiable within the central coil.

Two identical motorettes have been then instrumented with K-type thermocouples distributed in key locations - so that the hot-spot temperature could be captured - and processed through vacuum pressure impregnation (VPI). These have been partially thermally insulated through a Superwool ${ }^{\circledR} 607^{\circledR}$ $\mathrm{HT}^{\mathrm{TM}}$, following the layout illustrated in Fig. 1, and placed inside an environmental chamber as shown in Fig. 6. The motorettes are then employed for fine-tuning the "unaged" LPTN proposed in Section III.

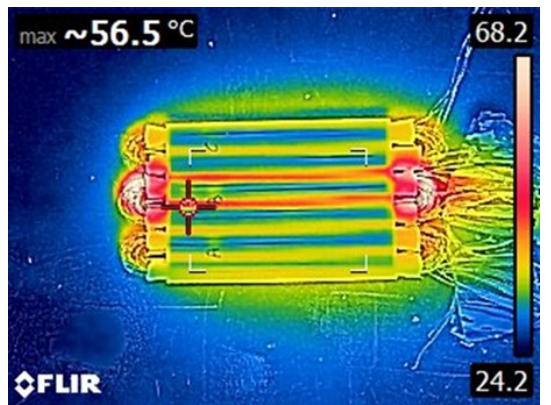

Fig. 5. Infrared signature analysis of the motorette fed through DC current.

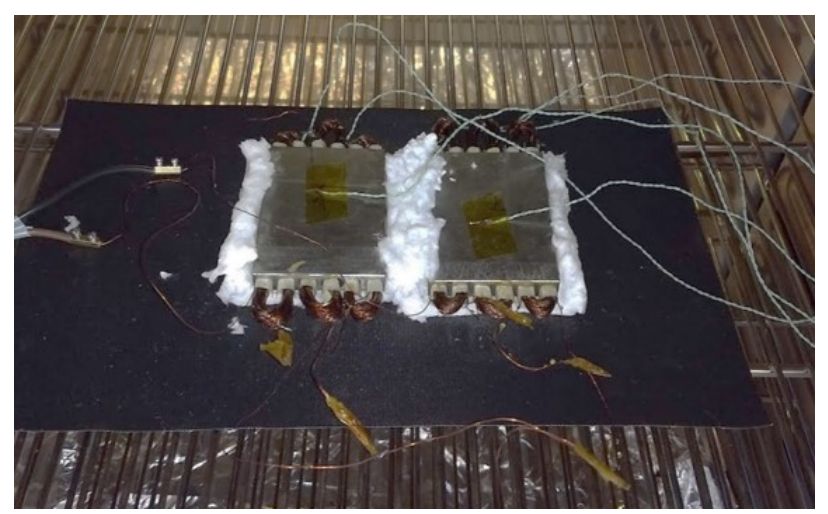

Fig. 6. Instrumented motorettes in an environmental chamber.

The windings are fed with a constant DC current, using a programmable power supply, and the temperatures are acquired through a data logger, connected to a personal computer. The recorded temperatures are imported in Matlab $^{\circledR}$, whilst the LPTN of Fig. 2 is implemented in Simulink ${ }^{\circledR}$ Simscape $^{\mathrm{TM}}$, which includes a thermal library for 
LPTNs simulation. In principle, the winding voltage drop could have been measured throughout these tests, and the instantaneous power could have been employed as loss input for the LPTN. However, in this work it has been preferred having the winding's DC current as a single input for the LPTN, and calculating the power loss based on the scheme in Fig. 3. Accordingly, the proposed LPTN can be actually used at the very early EM design stage for verifying how the geometry and winding parameters variations (e.g. number of turns, conductors cross section etc...) can influence the winding temperature distribution.

The thermal parameters listed in Table II are initially set in the LPTN. These are obtained from the manufacturers' datasheets [30] and from existing literature [31, 32]. The model is fine-tuned to match the experimentally recorded hotspot temperature. It must be noted that amongst all the critical parameters, only few of them play a major role on the hot-spot temperature evaluation. Consequently, the fine-tuning procedure was narrowed down to the three most sensitive parameters, namely, $k_{\text {slot }}, \gamma\left(i_{g}\right)$, and $\psi$, whose significance has been thoroughly discussed in Section III. The parameters identification is performed using the Simulink ${ }^{\circledR}$ Parameter Estimation toolbox. A non-linear least square optimization algorithm is selected for the identification procedure. Essentially, the three critical parameters are varied (within a physically-meaningful range) with the aim of minimizing the sum squared error between the measured and predicted temperatures. Table III reports their final, optimized values, for the unaged condition, whilst Fig. 7 shows the good agreement (i.e., instantaneous absolute error $<4{ }^{\circ} \mathrm{C}$ throughout the whole profile) between experimental and LPTN-predicted hot-spot temperature rise, for two different values of the winding current. Both motorettes, despite being randomly wound, show an identical thermal behavior in terms of hot-spot temperature. This agrees with the results presented in $[12,26]$, where it has been demonstrated that the relative position among the single wires in random windings has a negligible influence on the bulk thermal conductivity.

For sake of completeness, the resulting natural convection heat transfer coefficient $h_{\text {ext }}$ is plotted as function of the housing (stator) external temperature $\theta_{\text {ext }}$, in Fig. 8. Clearly, fixing a constant value for the natural convection coefficient, for transient thermal simulations, is an erroneous procedure. The proposed approach is thus a reasonable solution for tackling this important criticality of conventional LPTNs.

TABLE II

List OF PRE-DETERMINED DESIGN PARAMETERS

\begin{tabular}{ccc}
\hline \hline Parameter & Symbol & Value \\
\hline Impregnation conductivity [epoxy] & $k_{i n s}$ & $0.21 \mathrm{~W} / \mathrm{m} / \mathrm{K}$ \\
Copper conductivity & $k_{c u}$ & $386 \mathrm{~W} / \mathrm{m} / \mathrm{K}$ \\
Liner conductivity & $K_{n o m}$ & $0.123 \mathrm{~W} / \mathrm{m} / \mathrm{K}$ \\
Aluminum conductivity & $k_{a l u}$ & $136 \mathrm{~W} / \mathrm{m} / \mathrm{K}$ \\
Aluminum mass density & $d_{a l}$ & $2.7 \cdot 10^{3} \mathrm{~kg} / \mathrm{m}^{3}$ \\
Aluminum specific heat & $c_{a l}$ & $896 \mathrm{~J} / \mathrm{kg} / \mathrm{K}$ \\
Copper mass density & $d_{c u}$ & $8.95 \cdot 10^{3} \mathrm{~kg} / \mathrm{m}^{3}$ \\
Copper specific heat & $c_{c u}$ & $380 \mathrm{~J} / \mathrm{kg} / \mathrm{K}$ \\
Impregnation mass density & $d_{i n s}$ & $1.25 \cdot 10^{3} \mathrm{~kg} / \mathrm{m}^{3}$ \\
Impregnation specific heat & $c_{i n s}$ & $10^{3} \mathrm{~J} / \mathrm{kg} / \mathrm{K}$ \\
\hline \hline
\end{tabular}

Since the main objective of this study consists in evaluating how insulation thermal aging can vary the thermal behaviour of an EM, the rotor and the housing (i.e. frame) are not modelled. Nonetheless, it is important to note that when thermally modelling a complete EM, a set of additional critical thermal parameters needs to be experimentally finetuned, including: a) interference gaps between housing and lamination core, b) airgap thermal resistance and c) bearing thermal resistance.
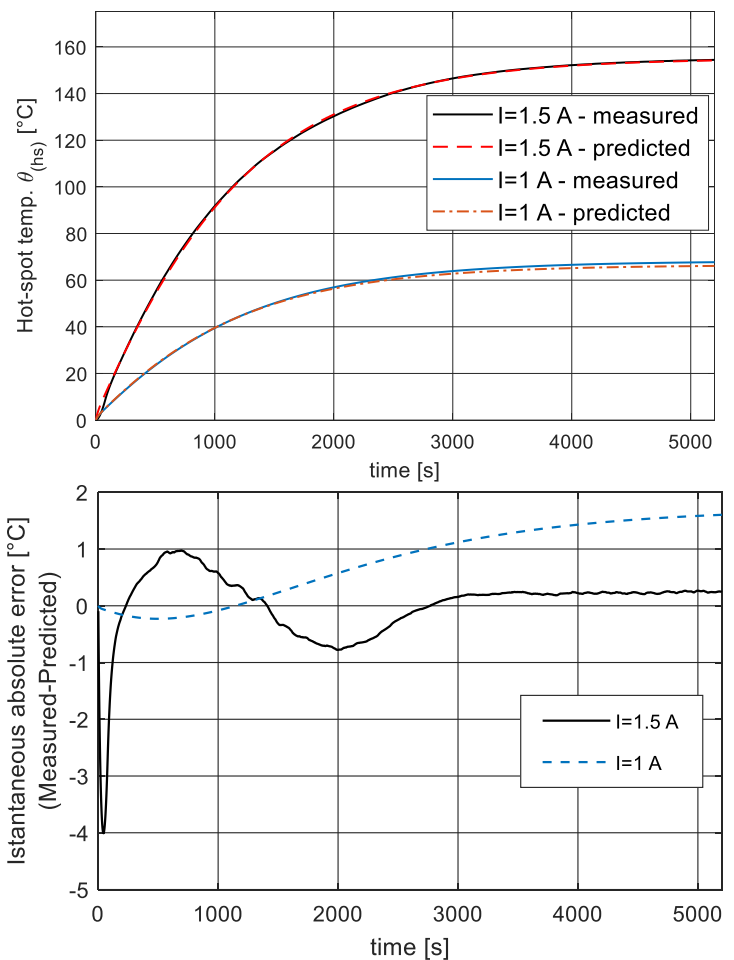

Fig. 7. Measured vs. LPTN-predicted hot-spot temperatures in the unaged condition (top sub-plot) and absolute error (bottom sub-plot).

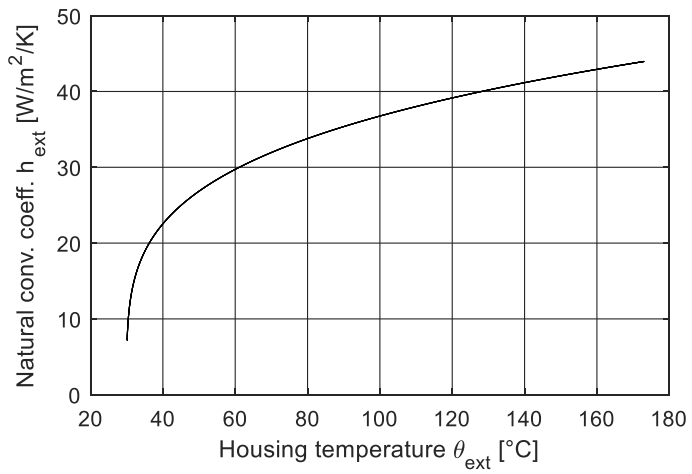

Fig. 8. Natural convection heat transfer coefficient as a function of the housing surface temperature.

TABLE III

Fine-TuNEd CRITICAL PARAMETERS (UNAGED CONDITION)

\begin{tabular}{ccc}
\hline \hline Parameter & Symbol & Value \\
\hline Equivalent slot conductivity & $k_{\text {slot }}$ & $0.295 \mathrm{~W} / \mathrm{m} / \mathrm{K}$ \\
Winding capacity corrective factor & $\gamma\left(i_{g}\right)$ & 0.58 \\
Natural convection corrective factor & $\psi$ & 0.63 \\
\hline \hline
\end{tabular}

\section{Thermal AgIng InfluENCE ON HEAT Transfer}

The availability of an accurate thermal model, such as the proposed LPTN, allows the user to investigate how the insulation thermal aging can influence the thermal behavior of an EM. This Section addresses such a particular topic through an experimental-based analysis.

\section{A. Thermal aging in EMs}

Thermal aging is surely considered as one of the main stressing factors affecting the lifetime and reliability of EMs' insulation systems [15, 33-35]. When an insulating material is subject to a high temperature, a number of Arrhenius-type 
reactions are triggered within the material's chemical bonds [36]. The thermal lifetime of EMs' insulation is conventionally modelled through a first order chemical reaction. Essentially, the dominant reaction, characterizing the aging process, is assumed to prevail over other secondary thermally-activated chemical changes within the material's structure. The onset of these reactions leads to cracks, delamination and in general structural weakening within the insulation [37], thus negatively impacting on its ability to provide dielectric separation. The thermal life of a solid insulating material operating at absolute temperature $\theta$ is calculated according to the Arrhenius-Dakin law as in (11), where $A$ and $B$ are material's dependent parameters to be extracted through accelerated aging tests [17].

$$
L=A \cdot \exp (B / \theta)
$$

The parameter $B$ in particular is the ratio between the activation energy of the dominant chemical reaction and the Boltzmann constant. The commonly employed "10 degrees rule", which states that the insulation life halves every time its temperature is increased by $10{ }^{\circ} \mathrm{C}$, is actually an approximation of (11) [38].

Accelerated thermal aging tests have been carried out on a set of 5 motorettes, identical to those shown in Fig. 6, but with a total of six coils each. The specimens have been thermally aged at a constant temperature of $230{ }^{\circ} \mathrm{C}$ in an environmental chamber. The aging temperature has been carefully selected for a) accelerating the thermal degradation process, and thus shortening the testing time to a reasonable level, and b) limiting the inception of secondary thermally-induced chemical reactions, which would be highly likely in case of tests at extremely high temperatures. Indeed, preliminary tests at 250 and $270{ }^{\circ} \mathrm{C}$ have shown excessive resin depolymerisation, which is a condition unlikely to be observed in an actual EM during normal operations. Tests at temperatures as close as possible to the (expected) in-service operating temperature might in principle provide slightly more accurate results. However, this would also extend the aging / testing time to several thousands of hours. Here it is important to remark that accelerated aging tests are the common practice for the thermal lifetime evaluation of EMs' insulation systems [39]. Despite the insulation has been aged through a constant temperature, recent work [33] has demonstrated that the thermal lifetime of EMs operating with short / variable duty is well modelled through the Arrhenius law (i.e. (11)). This indicates that the results presented here are also applicable to EMs whose winding is subject to dynamic temperature profiles.

The windings' turn to turn insulation system condition has been monitored throughout the thermal aging campaign, until an interturn fault is detected in all the coils. The selected end-of-life criterion is the dielectric breakdown, verified through the $\mathrm{AC}$ electric withstand test. During this diagnostic test, the specimen's insulation is stressed with an AC voltage of $500 \mathrm{~V}$, applied through a Megger ${ }^{\circledR}$ Delta 4000, as shown in Fig. 9. The specimen is considered as failed if a breakdown (i.e. short circuit - see Fig. 9) is detected during the voltage application (i.e. tripping of the Megger ${ }^{\circledR}$ generator). The adoption of this particular end-of-life criterion allows to directly apprise the obtained thermal endurance data with the Arrhenius plot of the winding's magnet wire, according to the technical standard IEC 60172 [40].

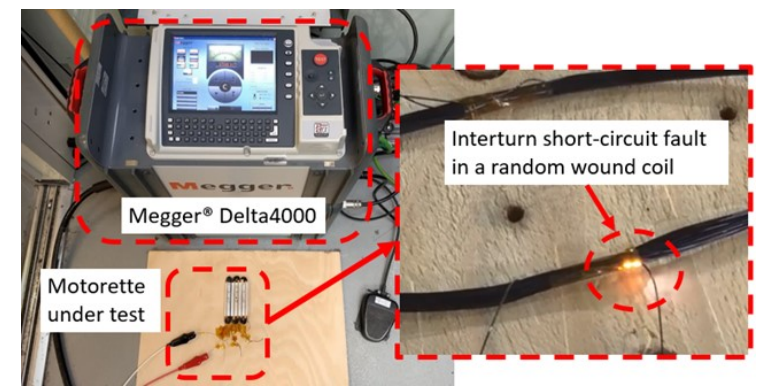

Fig. 9. Test setup for winding insulation diagnostic.

The obtained failure probability distribution plot is given in Fig. 10. Relying on the accelerated aging tests outcome, the obtained median of failure times is equal to 271 hours, and it is assumed as the maximum operational life of the EM at hand. In other words, if an EM, whose structure and materials match those of the analyzed motorette, is continuously operated at a temperature of $230{ }^{\circ} \mathrm{C}$, its expected lifetime would be 271 hours. It is worth remarking that such a temperature is well above the insulation thermal class (i.e., $200{ }^{\circ} \mathrm{C}$ ), and thus a real machine, whose hot-spot never exceeds the thermal class limit, would survive for a much longer timespan. However, it is also important to note that the thermal class declared by both magnet wire and resin manufacturers (i.e. $200^{\circ} \mathrm{C}$ ) refer to accelerated thermal aging tests carried out on twisted pairs specimens [33, 40]. The actual thermal class of the EM's insulation system can be strongly influenced by a) the winding layout / geometrical construction [33] and b) the chemical interaction between different materials in an impregnated winding [40].

At this stage, it is important to note that a thorough reliability assessment should employ the cumulative failure probability for a given (acceptable) percentile of failure time [41]. The latter would enable the adoption of a more stringent lifetime requirement (e.g., $1 \%$ probability of failure), which is advised for EMs operated in a safety-critical environment [42], e.g., transportation application. In this case, the EM's end-of-life would be reached once the cumulative failure probability becomes higher than the maximum acceptable probability of failure. Since this work is principally oriented at assessing the impact of the insulation aging on the EM thermal behavior, rather than on the EM reliability, the median of failure time is chosen as a criterion for defining the EM's lifetime. This choice represents a fair compromise between accuracy and computational effort, although a similar analysis could have been performed adopting any probability of failure.

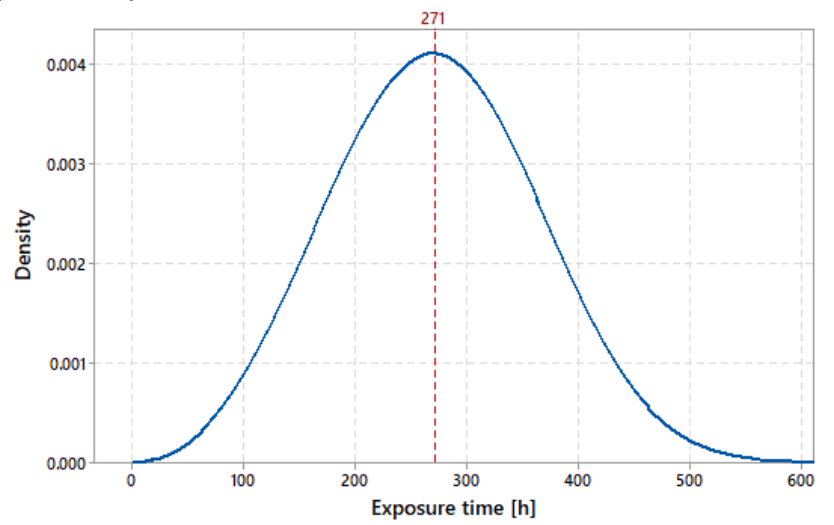

Fig. 10. Probability distribution plot of failure times for the motorettes aged at $230{ }^{\circ} \mathrm{C}$. 


\section{B. Experimental thermal behavior evaluation}

The two instrumented motorettes of Fig. 6 are thermallyaged at $230{ }^{\circ} \mathrm{C}$ to quantify the impact of the insulation aging on the heat transfer mechanism within the EM. In particular, a number of thermal exposure cycles are performed on the motorettes to progressively age the insulation. At the end of each exposure cycle, the thermal behavior of the motorette is assessed as done in Section IV, i.e., the winding is fed through a constant DC current and the motorettes temperatures are recorded. During the thermal assessment stage, the winding temperature is always kept below the insulation thermal class, in order to not induce any significant intrinsic aging. Further, the temperature inside the environmental chamber is controlled at $30{ }^{\circ} \mathrm{C}$ throughout the temperature profile acquisition. The flow chart summarizing the whole evaluation procedure is illustrated in Fig. 11. The results of the investigation are provided in Fig. 12, where the measured transient hot-spot temperature is plotted for four different aging levels, together with the absolute temperature variation (i.e., aged winding temperature profile(s) minus unaged case).

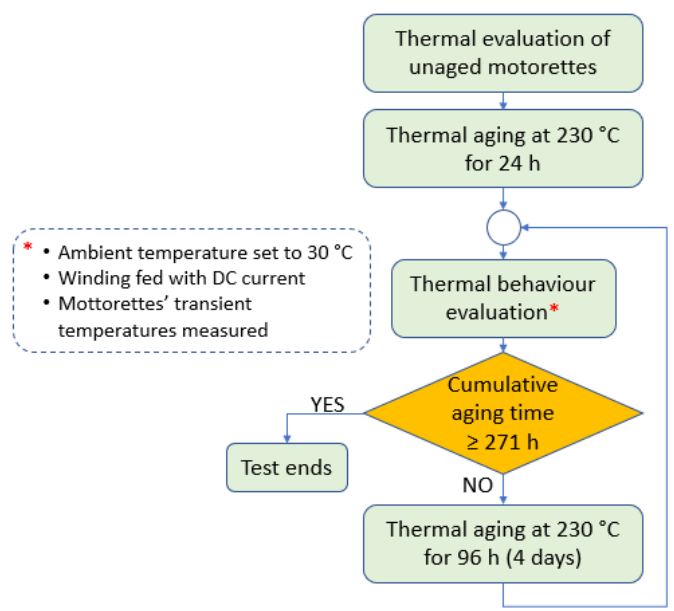

Fig. 11. Flow chart of the thermal evaluation procedure.
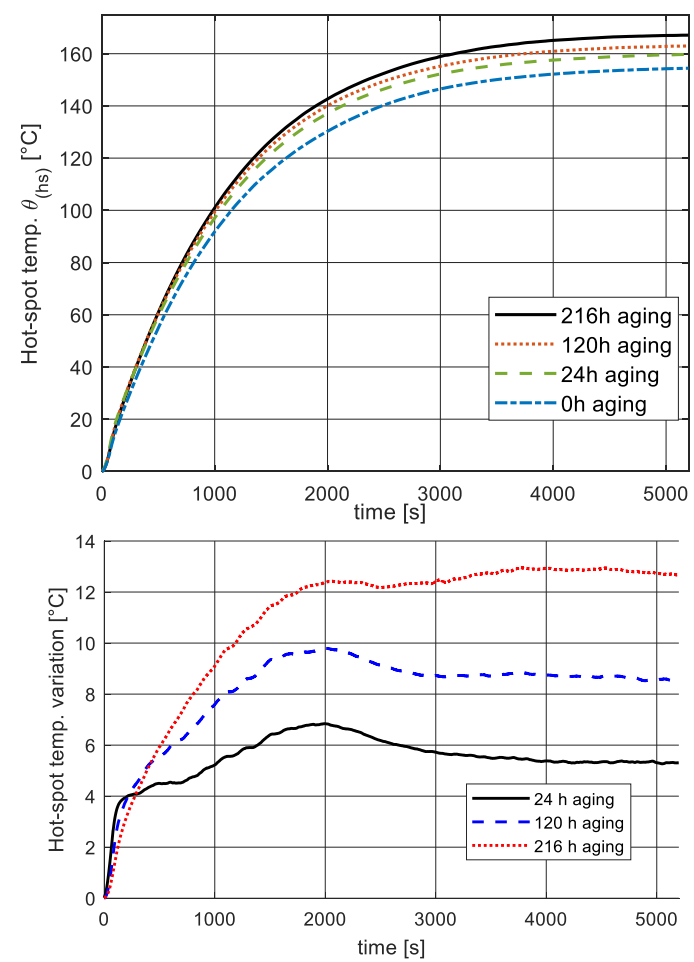

Fig. 12. Experimental hot-spot temperatures as a function of the thermal aging level (top sub-plot) and absolute temperature variation with respect to the unaged case (bottom sub-plot).
Interestingly, as the insulation lifetime progresses towards its end-of-life (i.e., the thermal aging accumulates), its capability of dissipating heat gradually decreases, causing a temperature rise in the slot. In other words, given two identical EMs, of which one is unaged, and the other has been in service for a certain time, then, the aged EM will have a higher hot-spot temperature for the same operating conditions.

\section{Impact of thermal aging on LPTN}

On the basis of the findings condensed in Fig. 12, the thermal aging has clearly an impact on the capability to dissipate heat from the winding hot-spot to the ambient air. Considering the LPTN presented in Section III and shown in Fig. 2, the two main thermal resistances with the largest temperature drop, between the hot-spot and the ambient air are: 1) the external natural convection thermal resistance and 2 ) the winding's equivalent thermal resistance. Obviously, the former is not directly affected by the insulation's thermal aging, as it just depends on geometrical dimensions of the interface body and on the temperature difference between the housing's outer surface and the ambient air (see (8)-(10)). However, the poor thermal performance, due to the insulation aging, leads to a higher temperature on heat exchange surface with respect to the unaged condition. Such a secondary effect is already modelled in the proposed LPTN, because the convection resistance is dynamically updated according to the actual outer surface temperature (see Section III.B).

On the contrary, the winding's equivalent conduction heat transfer coefficient (i.e., $k_{\text {slot }}$ ) is surely influenced by the thermal aging level. In fact, as indicated by (3), it depends on both copper and insulation conductivities. The parameter $k_{c u}$ is unaffected by the thermal aging, as the operating temperatures of conventional EMs are well below the values able to induce any quantifiable modification in the copper chemical/physical structure. Conversely, the insulation system materials (i.e., wire's enamel and impregnating resin) are polymers with organic chemical composition. They are intrinsically susceptible to thermophysical modifications, even when stored at standard ambient conditions [43]. In addition, the process of oxidative polymer degradation is accelerated under the effect of long-term exposition to high temperature [44, 45]. For these reasons, the winding's equivalent thermal resistance is the LPTN's element more exposed to the consequences of the thermal aging.

The LPTN presented in Section III and fine-tuned in Section IV is the candidate tool for quantifying the impact of thermal aging on the equivalent heat transfer coefficient in the EM's slot. Basically, it is assumed that the link between thermal aging level and hot-spot temperature variation, as indicated in Fig. 12, can be ascribed to the sole $k_{\text {slot }}$ variation. Hence, the LPTN fine-tuning procedure has been repeated employing the temperature profiles collected during the thermal behavior evaluation, while keeping unchanged all critical parameters (i.e., values resulting from the fine-tuning procedure carried out for the unaged LPTN) except $k_{\text {slot }}$. Accordingly, Table IV summarizes the results of this investigation, by listing the obtained $k_{\text {slot }}$ values, alongside with the winding's hot-spot temperature, at different aging levels. In Section VI these results will be discussed in detail.

For what concerns the thermal capacities, which are important for modeling the winding's transient temperature 
profile, it is found that the thermal aging does not have a considerable effect on them. This conclusion is supported by the trends of both measured and LPTN-predicted temperature profiles relative to the test after $216 \mathrm{~h}$ of thermal aging, which are plotted in Fig. 13. In this case, the instantaneous absolute error is $<5{ }^{\circ} \mathrm{C}$ throughout the full temperature profile, although the only parameter identified during the fine-tuning procedure of the aged LPTN is $k_{\text {slot }}$, (i.e. thermal capacities are held equal to the unaged values).

TABLE IV

WiNDING THERMAL CONDUCTIVITY VARIATION WITH AGING

\begin{tabular}{ccc}
\hline $\begin{array}{c}\text { Cumulative aging } \\
\text { at } 230{ }^{\circ} \mathbf{C}[\mathbf{h}]\end{array}$ & $\begin{array}{c}\boldsymbol{k}_{\text {slot }} \\
{[\mathbf{W} / \mathbf{m} / \mathbf{K}]}\end{array}$ & $\begin{array}{c}\text { Steady-state hot-spot } \\
\text { temp. rise }\left[{ }^{\circ} \mathbf{C}\right]\end{array}$ \\
\hline 0 & 0.295 & 154 \\
24 & 0.194 & 159 \\
120 & 0.164 & 163 \\
216 & 0.141 & 168 \\
\hline \hline
\end{tabular}
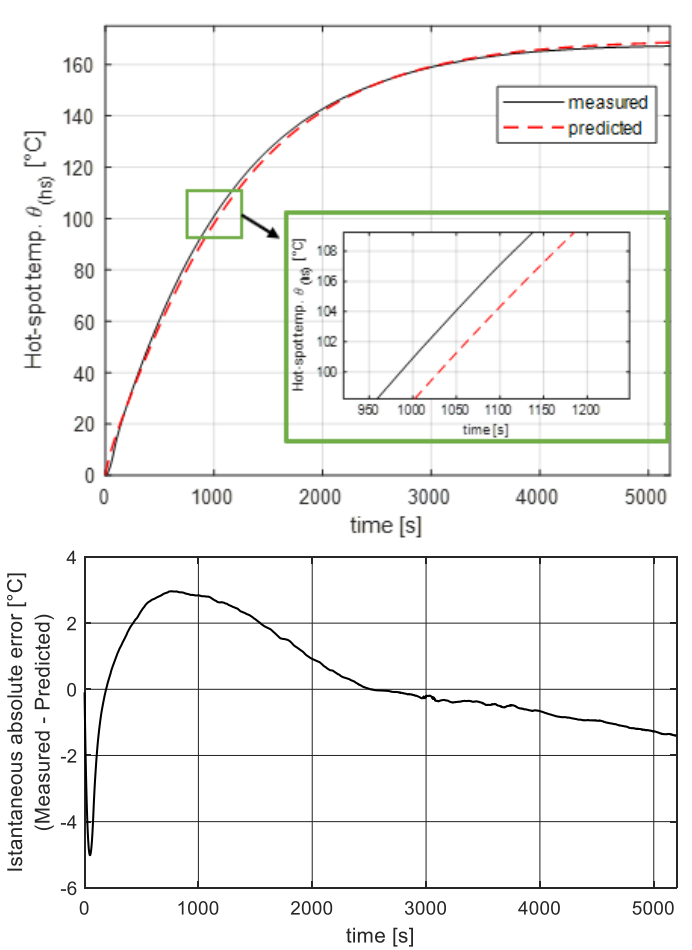

Fig. 13. Measured vs. predicted hot-spot temperature profiles after $216 \mathrm{~h}$ of thermal aging (top sub-plot) and absolute error (bottom sub-plot).

\section{FE Validation}

For further validating the accuracy of the proposed LPTN, a 2D thermal FE model of the motorette has been implemented in ANSYS $^{\circledR}$, by using the thermal parameters listed in Table II, suitably corrected by the data listed in Tables III and IV. The simulation outcome (steady-state condition) for two different thermal aging levels (i.e., 0 hours and 216 hours) is reported in Fig. 14.
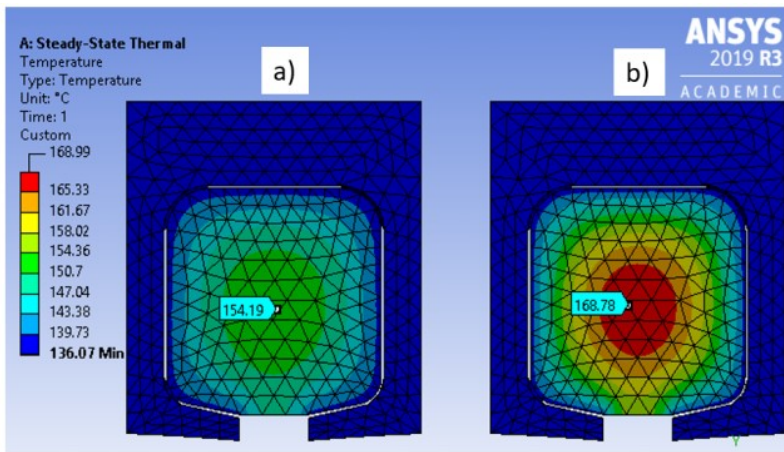

Fig. 14. Temperature distribution from thermal FE for the unaged (a) and thermally aged (i.e. $216 \mathrm{~h}$ ) (b) motorette.
The comparison is done by varying the equivalent slot conductivity from $0.295 \mathrm{~W} / \mathrm{K} / \mathrm{m}$ (i.e., unaged condition), to $0.141 \mathrm{~W} / \mathrm{K} / \mathrm{m}$ (i.e., 216 hours aging), based on the data reported in Table IV. An excellent match, in terms of hot-spot temperature is verified among experiments, LPTN and FE model.

\section{DISCUSSION AND APPLICABILITY}

Insulation thermal aging, which is often neglected during the EM thermal modeling, compromises the ability of the EM to dissipate heat, as proven by the experimental findings presented in Section V. In particular, the winding's equivalent conductivity considerably drops (due to the insulation aging) causing an increment in the hot-spot temperature. Considering just $24 \mathrm{~h}$ of thermal aging at $230{ }^{\circ} \mathrm{C}$, the $k_{\text {slot }}$ value decreases by more than $30 \%$, which corresponds to an increment of the steady-state hot-spot temperature of $5{ }^{\circ} \mathrm{C}$. As the EM moves towards its end-of-life, the winding thermal conductivity variation, with respect to its unaged value, can be as high as $50 \%$, relative to its original value. In the particular example considered in this paper, this resulted in a hot-spot temperature rise of about $14{ }^{\circ} \mathrm{C}$. Such a result provides extremely useful information to EM designers. Namely, if a newly-manufactured (i.e., unaged) EM is used for extracting / fine-tuning its thermal model, misleading results could be obtained. In fact, shortly after the EM goes into service, because of thermal aging, its hot-spot temperature might become higher than the predicted value. Such a detrimental effect keeps getting worse as the in-service time grows, causing a sort of domino effect. Concisely, the progressive increment in winding temperature accelerates even more the insulation's thermal aging, and so on.

Following the discussion of Section IV.a, the useful winding's insulation lifetime is assumed to be $271 \mathrm{~h}$ (when continuously operating at $230{ }^{\circ} \mathrm{C}$ ). This time span is defined hereinafter as " $100 \%$ damage". Fig. 15 provides a phenomenological fitting, where the variation of $k_{\text {slot }}$ with the insulation's cumulative damage (i.e., normalized by $271 \mathrm{~h}$ ), is interpolated by a logarithmic curve described by (12).

$$
k_{\text {slot }}=0.245-0.24 \cdot \log (\% \text { damage })
$$

Thus, if the Arrhenius curve (i.e., thermal endurance plot) of the EM's insulation is available, then the EM designer could theoretically predict a-priori how the machine's LPTN would change throughout its whole lifetime. This is extremely useful, as it allows EM designers and manufacturers to account for an appropriate thermal safety-factor during the EM's prototyping, in order to guarantee that during service operations the winding never exceeds a certain temperature, which is generally the insulation thermal class.

Once again, it is important to remark that a different endof-life point (i.e., 100\% damage) could be chosen, depending on the application's demanded reliability. This choice does not affect in any way the validity of the presented study.

Finally, Fig. 16 provides a flow chart for the practical implementation of the proposed methodology, for the design / analysis of an EM. It is worth observing that despite the presented study has been tailored for a naturally air-cooled $\mathrm{EM}$, it can be actually repeated for different cooling arrangements, winding layouts and power ratings. Although in the present work accelerated thermal aging tests have been performed at constant temperature, this does not preclude the 
application of the proposed methodologies to a machine operating with a time-variant temperature profile (i.e., dynamic operations), notwithstanding that the dominant stressor remains unchanged (i.e., temperature). In this case, the end-of-life point needs to be computed by combining the Arrhenius model (i.e. (11)) with the cumulative damage law, or Miner's rule, as described by the authors in [33] and in [41].

As this work focuses only on insulation thermal aging, the contribution of other stressing factors on the insulation lifetime has not been considered. For a given insulation system if extrinsic electrical stress (i.e., partial discharge (PD) inception) and thermal aging are combined the ensuing lifetime is shortened as opposed to the case where thermal aging acts as a stand-alone stress. However, it is important to note that the present work refers to machines with impregnated random windings (as indicated in Section II). EMs adopting random windings are insulated by Type I materials (i.e., organic chemical composition [46]). According to the technical standard IEC 60034-18-41, EMs with Type I insulation must operate in absence of PD (i.e., PD-free) throughout their whole lifetime [47]. Therefore, a single stress lifetime model, with temperature as the prevailing aging factor, is considered here.

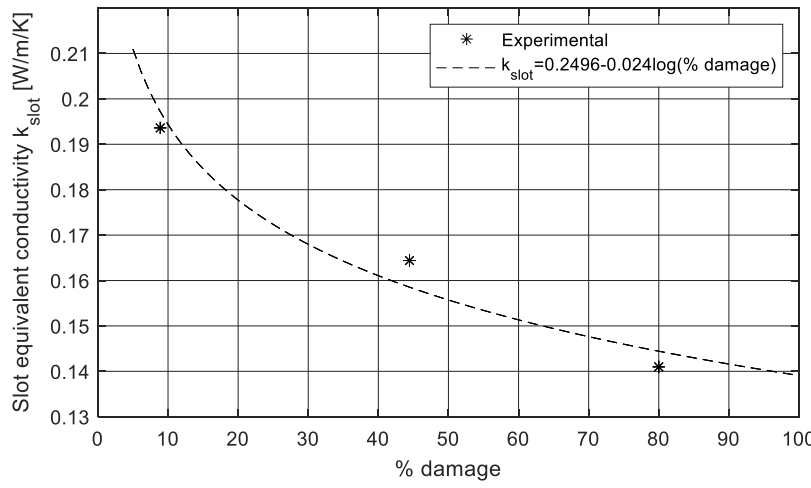

Fig. 15. Variation of the equivalent winding thermal conductivity with the insulation's cumulative damage.

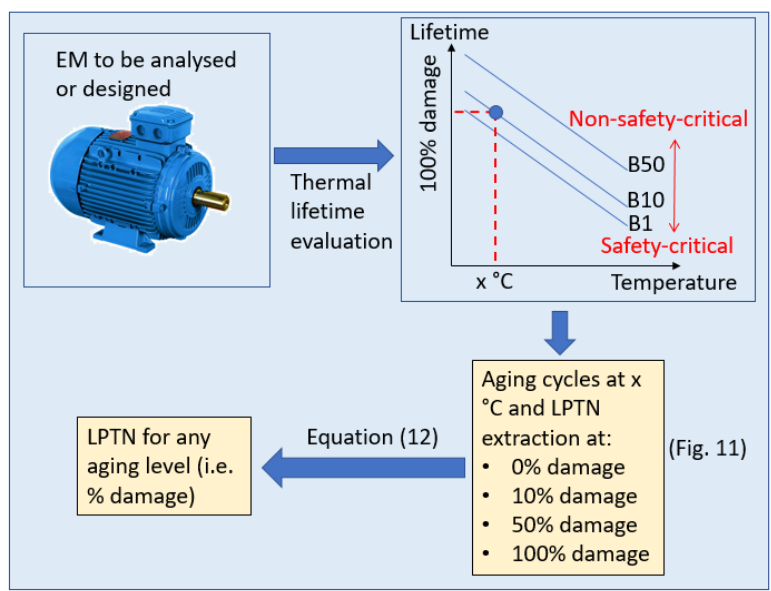

Fig. 16. Implementation of the proposed methodology at the EM design stage.

Nonetheless, if the present study is to be repeated for medium or high voltage EMs (i.e. mixed organic-inorganic insulation) [48], then the insulation lifetime modeling should also include the (deleterious) contribution of PD. It is important to point out that PD inception can surely influence the end-of-life instant. However, PD in themselves are localized phenomena, and thus they no effect whatsoever on the winding's thermal conductivity variation.

\section{CONCLUSIONS}

Thermal management plays a pivotal role in the design and operation of electrical machines. Uncontrolled high temperatures can negatively impact on the lifetime expectancy of the insulation system, compromising thus the reliability figures. Various recent publications have addressed the topics of thermal analysis of electrical machines and aging of electrical insulating systems, without, however, studying how both can be mutually influenced.

In this paper the influence of thermal aging on the capability of heat extraction is thoroughly investigated. An unconventional, lumped-parameter thermal network is introduced and experimentally fine-tuned for accounting for and quantifying the degradation of the thermal performance caused by the insulation aging. As opposed to conventional thermal modeling techniques, the proposed thermal network dynamically calculates the natural convention heat transfer coefficient, based on the machine's outer surface temperature. This enables a precise evaluation of the machine's hot-spot temperature even during transient (i.e. dynamic) operations.

The relationship between insulation thermal aging and winding equivalent thermal conductivity is clearly identified, through the aid of the proposed fine-tuned thermal model. As a main result, it is found that as an electrical machine ages, the equivalent thermal conductivity of its winding can decrease by as much as $50 \%$ compared to the unaged value. This results in the winding's hot-spot temperature increment, which in the analyzed case-study test sample is quantified to be c.a. $10 \%$ towards the end of its useful lifetime. The aforementioned result represents one of the main technical contributions and novelties of this paper, and might have a strong impact in the way electrical machines are thermally modelled. The analyses and methodologies presented in this paper can be easily implemented when designing a new electric motor or analyzing an existing one. These methodologies can thus represent an extremely useful reference for electrical machines designers, practicing engineers, and motor manufacturers, as they allow to account for a factor which is generally overlooked when thermally modelling a machine, namely, the insulation's system thermal aging.

\section{REFERENCES}

[1] J. Lee, H. Yeo, H. Jung, T. Kim, and J. Ro, "Electromagnetic and thermal analysis and design of a novel-structured surface-mounted permanent magnet motor with high-power-density," IET Electric Power Applications, vol. 13, no. 4, pp. 472-478, 2019.

[2] S. Nategh, A. Krings, O. Wallmark, and M. Leksell, "Evaluation of Impregnation Materials for Thermal Management of Liquid-Cooled Electric Machines," IEEE Transactions on Industrial Electronics, vol. 61, no. 11, pp. 5956-5965, 2014.

[3] V. Madonna, A. Walker, P. Giangrande, G. Serra, C. Gerada, and M. Galea, "Improved Thermal Management and Analysis for Stator EndWindings of Electrical Machines," IEEE Transactions on Industrial Electronics, vol. 66, no. 7, pp. 5057-5069, 2019.

[4] S. Ayat, H. Liu, F. Chauvicourt, and R. Wrobel, "Experimental Derivation of Thermal Parameters of the Stator- Winding Region in Thermal Analysis of PM Electrical Machines," in IECON 2018 - 44th Annual Conference of the IEEE Industrial Electronics Society, 2018, pp. 496-501.

[5] G. Bramerdorfer, A. Cavagnino, and S. Vaschetto, "Importance of thermal modeling for design optimization scenarios of induction motors," in 2017 IEEE Energy Conversion Congress and Exposition (ECCE), 2017, pp. 4666-4672.

[6] A. Boglietti, M. Cossale, M. Popescu, and D. A. Staton, "Electrical Machines Thermal Model: Advanced Calibration Techniques," IEEE 
Transactions on Industry Applications, vol. 55, no. 3, pp. 2620-2628 2019.

[7] P. Lindh et al., "Performance of a Direct-Liquid-Cooled Motor in an Electric Bus Under Different Load Cycles," IEEE Access, vol. 7, pp 86897-86905, 2019

[8] A. Boglietti, E. Carpaneto, M. Cossale, and S. Vaschetto, "StatorWinding Thermal Models for Short-Time Thermal Transients: Definition and Validation," IEEE Transactions on Industrial Electronics, vol. 63, no. 5, pp. 2713-2721, 2016.

[9] A. Boglietti, A. Cavagnino, and D. Staton, "Determination of Critical Parameters in Electrical Machine Thermal Models," IEEE Transactions on Industry Applications, vol. 44, no. 4, pp. 1150-1159, 2008.

[10] V. Madonna, P. Giangrande, C. Gerada, and M. Galea, "Thermal analysis of fault-tolerant electrical machines for aerospace actuators," IET Electric Power Applications, vol. 13, no. 7, pp. 843-852, 2019.

[11] N. Simpson, R. Wrobel, and P. H. Mellor, "Estimation of Equivalent Thermal Parameters of Impregnated Electrical Windings," IEEE Transactions on Industry Applications, vol. 49, no. 6, pp. 2505-2515 2013.

[12] R. Wrobel, S. J. Williamson, J. D. Booker, and P. H. Mellor, "Characterizing the in situ Thermal Behavior of Selected Electrical Machine Insulation and Impregnation Materials," IEEE Transactions on Industry Applications, vol. 52, no. 6, pp. 4678-4687, 2016.

[13] C. Sciascera, P. Giangrande, L. Papini, C. Gerada, and M. Galea, "Analytical Thermal Model for Fast Stator Winding Temperature Prediction," IEEE Transactions on Industrial Electronics, vol. 64, no. 8, pp. 6116-6126, 2017

[14] V. Madonna, P. Giangrande, and M. Galea, "Evaluation of Strand-to-Strand Capacitance and Dissipation Factor in Thermally Aged Enameled Coils for Low voltage Electrical Machines," IET Science, Measurement \& Technology, vol. 13, no. 8, pp. 1170-1777, 2019.

[15] K. N. Gyftakis, M. Sumislawska, D. F. Kavanagh, D. A. Howey, and M. D. McCulloch, "Dielectric Characteristics of Electric Vehicle Traction Motor Winding Insulation Under Thermal Aging," IEEE Transactions on Industry Applications, vol. 52, no. 2, pp. 1398-1404 2016.

[16] M. Farahani, E. Gockenbach, H. Borsi, K. Schafer, and M. Kaufhold, "Behavior of machine insulation systems subjected to accelerated thermal aging test," IEEE Transactions on Dielectrics and Electrical Insulation, vol. 17, no. 5, pp. 1364-1372, 2010.

[17] V. Madonna, P. Giangrande, G. Migliazza, G. Buticchi, and M. Galea "A Time-Saving Approach for the Thermal Lifetime Evaluation of Low Voltage Electrical Machines," IEEE Transactions on Industrial Electronics, pp. 1-1, 2019.

[18] W. Shi and X. Zhou, "Online Estimation Method for Permanent Magnet Temperature of High-Density Permanent Magnet Synchronous Motor," IEEJ Transactions on Electrical and Electronic Engineering, vol. 15, no. 5, pp. 751-756, 2020.

[19] O. Wallscheid and J. Böcker, "Fusion of direct and indirect temperature estimation techniques for permanent magnet synchronous motors," in 2017 IEEE International Electric Machines and Drives Conference (IEMDC), 2017, pp. 1-8.

[20] M. Galea, P. Giangrande, V. Madonna, and G. Buticchi, "Insulation systems for electrical machines: Reliability MUST become a main design objective," IEEE Industrial Electronics Magazine, vol. 14, no. 1 , 2020 .

[21] S. J. Williamson, R. Wrobel, J. Yon, J. D. Booker, and P. H. Mellor, "Investigation of equivalent stator-winding thermal resistance during insulation system ageing," in 2017 IEEE 11th International Symposium on Diagnostics for Electrical Machines, Power Electronics and Drives (SDEMPED), 2017, pp. 550-556.

[22] Y. Gai et al., "Cooling of Automotive Traction Motors: Schemes, Examples, and Computation Methods," IEEE Transactions on Industrial Electronics, vol. 66, no. 3, pp. 1681-1692, 2019.

[23] D. A. Staton and A. Cavagnino, "Convection heat transfer and flow calculations suitable for electric machines thermal models," IEEE Transactions on Industrial Electronics, vol. 55, no. 10, pp. 3509-3516, 2008.

[24] L. Idoughi, X. Mininger, F. Bouillault, L. Bernard, and E. Hoang, "Thermal Model With Winding Homogenization and FIT Discretization for Stator Slot," IEEE Transactions on Magnetics, vol. 47, no. 12, pp 4822-4826, 2011.

[25] P. Romanazzi, J. Gyselinck, M. Bruna, and D. A. Howey, "Electromagnetic and thermal homogenisation of an electrical machine slot," in 2016 XXII International Conference on Electrical Machines (ICEM), 2016, pp. 1643-1649.

[26] A. Boglietti, M. Cossale, S. Vaschetto, and T. Dutra, "Thermal Conductivity Evaluation of Fractional-Slot Concentrated-Winding Machines," IEEE Transactions on Industry Applications, vol. 53, no. 3, pp. 2059-2065, 2017

[27] H. Yeo, H. Park, J. Seo, S. Jung, J. Ro, and H. Jung, "Electromagnetic and Thermal Analysis of a Surface-Mounted Permanent-Magnet Motor with Overhang Structure," IEEE Transactions on Magnetics, vol. 53, no. 6, pp. 1-4, 2017.

[28] F. P. Incropera, A. S. Lavine, T. L. Bergman, and D. P. DeWitt, Fundamentals of heat and mass transfer. Wiley, 2007.

[29] J. R. Lloyd and W. R. Moran, "Natural Convection Adjacent to Horizontal Surface of Various Planforms," Journal of Heat Transfer, vol. 96, no. 4, pp. 443-447, 1974

[30] "Elantas Electrical Insulation: Epoxylyte- (R) TSA 220 Technical Datasheet.," ed.

[31] W. Tong, Mechanical Design of Electric Motors. Taylor \& Francis, 2014.

[32] J. Pyrhonen, T. Jokinen, and V. Hrabovcova, Design of rotating electrical machines. John Wiley \& Sons, 2009.

[33] V. Madonna, P. Giangrande, L. Lusuardi, A. Cavallini, C. Gerada, and M. Galea, "Thermal Overload and Insulation Aging of Short Duty Cycle, Aerospace Motors," IEEE Transactions on Industrial Electronics, vol. 67, no. 4, pp. 2618-2629, 2020.

[34] K. N. Gyftakis, P. A. Panagiotou, N. Lophitis, D. A. Howey, and M. D. McCulloch, "Breakdown resistance analysis of traction motor winding insulation under thermal ageing," in 2017 IEEE Energy Conversion Congress and Exposition (ECCE), 2017, pp. 5819-5825.

[35] G. C. Stone, I. Culbert, E. A. Boulter, and H. Dhirani, Electrical Insulation for Rotating Machines: Design, Evaluation, Aging, Testing, and Repair. Wiley, 2014.

[36] G. C. Montanari and L. Simoni, "Aging phenomenology and modeling," IEEE Transactions on Electrical Insulation, vol. 28, no. 5, pp. 755-776, 1993.

[37] M. S. Naidu and M. K. NAIDU, High voltage engineering. Tata McGraw-Hill Education, 2013.

[38] T. W. Dakin, "Electrical Insulation Deterioration Treated as a Chemical Rate Phenomenon," Transactions of the American Institute of Electrical Engineers, vol. 67, no. 1, pp. 113-122, 1948.

[39] "IEEE Standard Test Procedure for Thermal Evaluation of Systems of Insulating Materials for Random-Wound AC Electric Machinery," IEEE Std 117-2015 (Revision of IEEE Std 117-1974), pp. 1-34, 2016.

[40] IEC 60172:2015 Test procedure for the determination of the temperature index of enamelled and tape wrapped winding wires, 2015.

[41] P. Giangrande, V. Madonna, S. Nuzzo, and M. Galea, "Moving Toward a Reliability-Oriented Design Approach of Low-Voltage Electrical Machines by Including Insulation Thermal Aging Considerations," IEEE Transactions on Transportation Electrification, vol. 6, no. 1, pp. 16-27, 2020.

[42] P. Giangrande et al., "Considerations on the Development of an Electric Drive for a Secondary Flight Control Electromechanical Actuator," IEEE Transactions on Industry Applications, vol. 55, no. 4, pp. 35443554, 2019.

[43] J. M. Hutchinson, "Physical aging of polymers," Progress in polymer science, vol. 20, no. 4, pp. 703-760, 1995.

[44] M. C. Celina, "Review of polymer oxidation and its relationship with materials performance and lifetime prediction," Polymer Degradation and Stability, vol. 98, no. 12, pp. 2419-2429, 2013/12/01/ 2013.

[45] W. Fan, J.-1. Li, Y.-y. Zheng, T.-j. Liu, X. Tian, and R.-j. Sun, "Influence of thermo-oxidative aging on the thermal conductivity of carbon fiber fabric reinforced epoxy composites," Polymer Degradation and Stability, vol. 123, pp. 162-169, 2016/01/01/ 2016.

[46] IEC 60034-18-41:2014 Rotating electrical machines - Part 18-41: Partial discharge free electrical insulation systems (Type I) used in rotating electrical machines fed from voltage converters - Qualification and quality control tests 2014.

[47] V. Madonna, P. Giangrande, W. Zhao, H. Zhang, C. Gerada, and M. Galea, "On the Design of Partial Discharge-Free Low Voltage Electrical Machines," in 2019 IEEE International Electric Machines \& Drives Conference (IEMDC), 2019, pp. 1837-1842.

[48] IEC 60034-18-42:2017 Rotating Electrical Machines - Part 18-42: Partial discharge resistant electrical insulation systems (Type II) used in rotating electrical machines fed from voltage converters Qualification tests, 2017. 


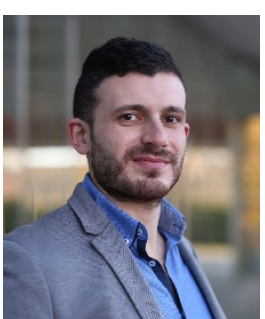

Vincenzo Madonna (M'17) received the Laurea Magistrale Degree in Electrical Engineering from the University of Bologna, Italy, in 2016, and the $\mathrm{PhD}$ Degree in Electrical Machines Design from the University of Nottingham, UK, in 2020. In 2016 he was awarded the prestigious Marie Skłodowska-Curie Fellowship and he joined the Institute for Aerospace Technology at the University of Nottingham, UK as a Doctoral

Fellow in reliability-oriented design of electrical machines for transportation. Throughout 2018, he was a Research Associate and Teaching Assistant with the Key Laboratory of More Electric Aircraft of Zhejiang Province, Ningbo, China. He is currently a Research Fellow with the Propulsion Futures Beacon of Excellence at the University of Nottingham, UK. During his 3-year PhD programme he has authored more than 25 scientific papers, published in various IEEE Transactions and IEEEsponsored conferences. His research interests include design, thermal management and lifetime prediction modelling of electrical machines.

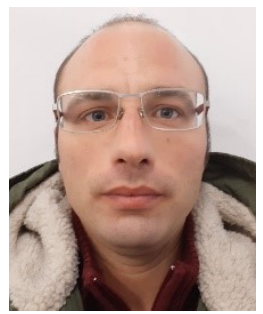

Paolo Giangrande (M'12-SM'19) received the Bachelor's (Hons.) and Master's (Hons.) degrees in electrical engineering at the Politecnico of Bari in 2005 and 2008, respectively. He received his PhD in electrical engineering at the Politecnico of Bari in 2011. Since 2012, he was Research Fellow at the University of Nottingham (UK), within the Power Electronics, Machines and Control Group. In 2018, he was appointed Senior Research Fellow and he is currently head of the Accelerated Lifetime Testing Laboratory at the Institute of Aerospace Technology, Nottingham. His main research interests include sensorless control of AC electric drives, design and testing of electromechanical actuators for aerospace, thermal management of high-performance electric drives and lifetime modelling of electrical machines.

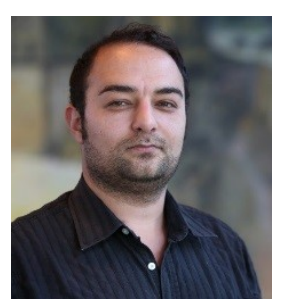

Michael Galea (M'13-SM'18) received the Ph.D degree in electrical machines design in 2013 from the University of Nottingham, Nottingham, U.K. $\mathrm{He}$ was appointed as Lecturer in 2014, as Associate Professor in 2018 and as Professor in Electrical Machines and Drives in 2019, all with the University of Nottingham. He is currently the Head of School of Aerospace, University of Nottingham Ningbo China, where he is also the Director of Aerospace. He currently lectures in Electrical Machines and Drives and in Aerospace Systems Integration and manages a number of diverse projects and programmes related to the more/all electric aircraft, electrified propulsion, and associated fields. His main research interests include design and development of electrical machines and drives (classical and unconventional), reliability and lifetime degradation of electrical machines and the more electric aircraft. Michael is a Fellow of the Royal Aeronautical Society, a Senior Member of the IEEE and sits on the Executive Board of the UK Magnetics Society. 